Louisiana State University

LSU Digital Commons

$1-14-2020$

\title{
Synergetic effect on catalytic activity and charge transfer in Pt-Pd bimetallic model catalysts prepared by atomic layer deposition
}

\author{
Moon Hyung Jang \\ The University of Alabama in Huntsville \\ Orhan Kizilkaya \\ Louisiana State University \\ A. Jeremy Kropf \\ Argonne National Laboratory \\ Richard L. Kurtz \\ Louisiana State University \\ Jeffrey W. Elam \\ Argonne National Laboratory
}

See next page for additional authors

Follow this and additional works at: https://digitalcommons.Isu.edu/physics_astronomy_pubs

\section{Recommended Citation}

Jang, M., Kizilkaya, O., Kropf, A., Kurtz, R., Elam, J., \& Lei, Y. (2020). Synergetic effect on catalytic activity and charge transfer in Pt-Pd bimetallic model catalysts prepared by atomic layer deposition. Journal of Chemical Physics, 152 (2) https://doi.org/10.1063/1.5128740

This Article is brought to you for free and open access by the Department of Physics \& Astronomy at LSU Digital Commons. It has been accepted for inclusion in Faculty Publications by an authorized administrator of LSU Digital Commons. For more information, please contact ir@lsu.edu. 


\section{Authors}

Moon Hyung Jang, Orhan Kizilkaya, A. Jeremy Kropf, Richard L. Kurtz, Jeffrey W. Elam, and Yu Lei 


\title{
Synergetic Effect on Catalytic Activity and Charge Transfer in Pt-Pd Bimetallic Model Catalysts Prepared by Atomic Layer Deposition
}

Moon-Hyung Jang ${ }^{1}$, Orhan Kizilkaya, ${ }^{2}$ A. Jeremy Kropf ${ }^{4}$ Richard L. Kurtz, ${ }^{2,3}$ Jeffrey W. Elam, ${ }^{5}$ Yu Lei ${ }^{1, a)}$

\author{
AFFILICATIONS \\ ${ }^{1}$ Department of Chemical and Materials Engineering, University of Alabama in Huntsville, \\ Huntsville AL, 35899 USA \\ ${ }^{2}$ Center for Advanced Microstructures and Devices, ${ }^{3}$ Department of Physics and Astronomy, \\ Louisiana State University, Baton Rouge LA, 70806 USA \\ ${ }^{4}$ Chemical Sciences and Engineering Division, ${ }^{5}$ Energy Systems Division, Argonne National \\ Laboratory, Lemont IL, 60439 USA
}

a) Author to whom correspondence should be addressed: yu.lei@uah.edu 


\begin{abstract}
Pt-Pd bimetallic nanoparticles were synthesized on $\mathrm{TiO}_{2}$ support on the planar substrate as well as high surface area $\mathrm{SiO}_{2}$ gel by atomic layer deposition (ALD) to identify the catalytic performance improvement after forming Pt-Pd bimetallic nanoparticles by the surface analysis techniques. From X-ray absorption near edge spectra (XANES) of Pt-Pd bimetallic nanoparticles, $d$-orbital hybridization between $\mathrm{Pt} 5 d$ and $\mathrm{Pd} 4 d$ was observed which is responsible for charge transferring from Pt to Pd. Moreover, it was found that Pt-Pd nanoparticles has a Pd shell/Pt core structure from the in-situ grazing incidence X-ray absorption spectroscopy (GI-XAS) study with CO adsorption. Resonant photoemission spectroscopy (RPES) on Pt-Pd bimetallic nanoparticles showed that Pd resonant intensity is enhanced compared to Pd monometallic nanoparticles because of $d$-orbital hybrization and electronic states broadening of $\mathrm{Pt}$ and $\mathrm{Pd}$ compared monometallic catalysts, which results in the catalytic performance improvement.
\end{abstract}




\section{INTRODUCTION}

Platinum (Pt) based nano-materials have been studied extensively for their exceptional catalytic behaviors. ${ }^{1,2}$ Due to platinum's high price and low reservoir, it is very important to minimize its usage. One of the frequently used methods to reduce the amount of $\mathrm{Pt}$ in the catalytic system is synthesizing bimetallic alloys with Pt and other metals without losing its catalytic properties. ${ }^{3-10}$ In fact, Pt based bimetallic catalysts provide the synergetic effect of combining each components so that the catalytic performance, selectivity, as well as stability can be improved when the bimetallic structure and composition are fine-tuned. ${ }^{11-14} \mathrm{Pt}-\mathrm{Pd}$ bimetallic nano-catalysts on oxide support are the one of the most studied bimetallic catalysts, ${ }^{15,16}$ owing to their excellent performance in aromatics hydrogenation, ${ }^{17}$ petroleum hydrocracking, ${ }^{18}$ emission control, ${ }^{19}$ hydrogen storage, ${ }^{20}$ and electrocatalysis in fuel cells. ${ }^{21}$ Moreover, Pt-Pd bimetallic nano-catalysts show an improved sulfur resistance in a process of hydrogenation of aromatics. ${ }^{17}$ However, the Pt bimetallic catalyst structure-performance relationship still needs to be established for the targeted chemical reactions.

Industrial catalysts are typically in the form of powder before being pressed and extruded into solid pellets of various shape. This morphology hinders various surface analysis techniques at the atomic level. To identify the electronic as well as the structural configurations of the catalysts in detail, it is required to manage the number of variables for the controlled experiments. For this purpose, single crystal substrates have been studied as simplified model catalysts under ultrahigh vacuum (UHV) conditions to understand the fundamental behavior of catalytic systems. ${ }^{22,23}$ This approach does not address some important factors such as the role of catalysts particle size and the influence of the support materials. To imitate the actual catalyst-support system, physical vapor deposition (PVD) of metal on metal oxide substrates was developed under UHV 
conditions. ${ }^{24-27}$ However, discrepancies in structure and performance relationship were found between industrial catalysts and model catalysts. "Pressure gap" and "materials gap" have been the focus on bridging the studies of industrial and model catalysts. One other possible issue that has limited discussion in the literature is the "synthesis gap". "Synthesis gap" between industrial and model catalysts is caused by differences in preparation methods. Industrial catalysts are often prepared using chemical methods with the presence of water and/or moisture and possible inorganic contaminations such as chloride, while the model catalysts are prepared by PVD of high purities with no or little presence of surface water under UHV conditions. This difference may cause departure from imitating the industrial catalysts with different morphologies and compositions. In addition, it is challenging to provide conformal coverage of metal nanoparticles and oxide supports on high aspect ratio substrates using PVD. To overcome this "synthesis gap", an alternative way to prepare identical nanoparticles and oxide thin films on both planar substrates and high surface area materials are highly desired.

Atomic Layer deposition (ALD) produces a conformal coating by a sequential exposure of gas phase precursors for the growth of thin oxide films and uniform metal nanoparticles. ${ }^{29-34}$ ALD has been utilized to prepare solid catalysts and achieved improving stability, reactivity, and selectivity. ${ }^{35-38}$ Because ALD is controlled by self-limiting surface reactions, it is possible to grow almost identical catalytic systems on both planar substrates and high surface area materials. ${ }^{39,40}$ ALD has been successfully adopted to produce alumina thin film supports for model silver catalysts ${ }^{41}$ and protecting layers for powder palladium catalysts. ${ }^{42}$ Therefore, ALD is a promising candidate to resolve the discrepancy between the model and the industrial catalytic systems. Oxide supports as well as metal nanoparticles that have precisely controlled compositions and particle sizes can be deposited by ALD in both planar model and practical 
catalyst systems. ${ }^{43}$ In addition, it is worth using planar model catalysts within ALD systems even though they do not have high surface areas like commercialized catalysts because surface sensitive characterization techniques such as photoemission spectroscopy can be performed to understand detailed structural and electronic configurations. Moreover, the number of parameters can be easily controlled and minimized in planar model catalysis.

Supported Pt-Pd bimetallic nanoparticles have been synthesized prepared using ALD. ${ }^{3,44,45}$ In our previous report, Pt-Pd bimetallic nanoparticles with $1 \mathrm{~nm}$ diameter were synthesized by ALD on $\mathrm{TiO}_{2}$ support/SiO 2 gel. ${ }^{45}$ Extended X-ray absorption fine structure (EXAFS) results showed that Pt-Pd bimetallic nanoparticles form a Pt-core/Pd-shell structure regardless of the growth temperature and pulse sequence. Density functional theory (DFT) calculations were performed to find out the lowest energy configuration for Pt-Pd bimetallic nanoparticles. There was no preferred surface configuration for either a Pt or Pd rich surface in vacuum while Pd-rich surface was more stable after adsorption of hydrogen monolayer. In this report, Pt-Pd bimetallic nanoparticles were synthesized on $\mathrm{TiO}_{2}$ thin films on a planar substrate instead of $\mathrm{SiO}_{2}$ gel to identify the change in their catalytic performance after forming Pt-Pd bimetallic nanoparticles. EXAFS fitting shows Pt-Pd nanoparticles on $\mathrm{TiO}_{2}$ thin films have almost same bonding characteristics with those on $\mathrm{TiO}_{2}$ support/SiO 2 gel. In addition, $d$-orbital hybridization between Pt $5 d$ and $\mathrm{Pd} 4 d$ was observed which is responsible for charge transferring from $\mathrm{Pt}$ to $\mathrm{Pd}$. Resonant Photoemission Spectra (RPES) of Pt-Pd bimetallic nanoparticles showed that Pd resonance is enhanced compared to Pd monometallic nanoparticles owing to the hybridization between Pt to Pd. The RPES indicates that the electronic configuration of Pt-Pd bimetallic nanoparticles has been altered significantly compared to monometallic catalysts which results in the catalytic performance improvement. 


\section{EXPERIMENTAL}

$\mathrm{Pt}-\mathrm{Pd} / \mathrm{TiO}_{2} / \mathrm{Si}(100)$ and $\mathrm{Pt}-\mathrm{Pd} / \mathrm{TiO}_{2} /$ fused silica model catalysts and $\mathrm{Pt}-\mathrm{Pd} / \mathrm{TiO}_{2} / \mathrm{SiO}_{2}$ gel practical catalysts were prepared simultaneously in a viscous flow hot-walled ALD system. ${ }^{45,46}$ Ultrahigh purity $\mathrm{N}_{2}$ carrier gas (Air-gas, 99.999\%) was purified once again using an Aeronex Gatekeeper Inert Gas Filter by trapping oxygen-containing impurities right before entering the ALD reactor.

$1 \mathrm{~mm}$ thick high purity polished fused silica (Technical Glass Products) and $0.5 \mathrm{~mm}$ thick $n$ $\operatorname{Si}(100)$ wafers (SQI, Inc) were used as substrates for model catalysts. The $\mathrm{Si}(100)$ wafer has a 17 $\AA$ thick native $\mathrm{SiO}_{2}$ layer which is measured by spectroscopic ellipsometry. The $\mathrm{SiO}_{2}$ gel (Silicycle S10040 M silica gel) has about $100 \mathrm{~m}^{2} \mathrm{~g}^{-1}$ surface area with a particle size of $75-200$ $\mu \mathrm{m}$, and a pore diameter of $30 \mathrm{~nm}$. Pre-baked $\mathrm{SiO}_{2}$ gel $(0.5 \mathrm{~g})$ was uniformly distributed on a stainless steel mesh on the stainless steel sample tray which also contains the $\mathrm{Si}(100)$ and fused silica substrates. The sample tray was loaded to the center of the ALD reactor and baked for 30 min at $200{ }^{\circ} \mathrm{C}$ with a $350 \mathrm{sccm} \mathrm{N}_{2}$ flow under 1 Torr for thermal stabilizing of samples and outgassing of the $\mathrm{SiO}_{2}$ gel. Then the samples were in-situ cleaned by $10 \%$ ozone in $\mathrm{O}_{2}$ with a 30 sccm flow rate under 1 Torr at $200{ }^{\circ} \mathrm{C}$ for 15 min before ALD deposition. It has been reported that ALD Pt and Pd nucleation is more efficient on $\mathrm{TiO}_{2}$ than $\mathrm{SiO}_{2}{ }^{47,48}$ After cleaning, $3 \AA$ thick $\mathrm{TiO}_{2}$ deposition was made on the substrates by 5 cycles of $\mathrm{TiO}_{2} \mathrm{ALD}$ to promote $\mathrm{Pt}$ and $\mathrm{Pd}$ nucleation. The bare $\mathrm{SiO}_{2}$ gel yielded only about $0.1 \mathrm{wt} \%$ gain for $\mathrm{Pd} \mathrm{TiCl}_{4}$ (Sigma-Aldrich, 99.9\%) and deionized water were used as precursors alternatively at $150{ }^{\circ} \mathrm{C}$. The thickness of $\mathrm{TiO}_{2}$ films on $\mathrm{Si}(100)$ were measured by spectroscopic ellipsometry which were deposited on $\mathrm{SiO}_{2}$ gel in the same batch. The weight gain of the $\mathrm{SiO}_{2}$ gel by $\mathrm{TiO}_{2}$ was measured to confirm 
$\mathrm{TiO}_{2}$ film thicknesses. The thickness differences between these two methods were within $10 \%$ range.

$\mathrm{Pt}$ was grown on $\mathrm{TiO}_{2}$ coated samples by alternating exposures to trimethyl(methylcyclopentadienyl) platinum ( $\mathrm{Pt}(\mathrm{MeCp}) \mathrm{Me}_{3}$, Sigma-Aldrich,98\%) and $\mathrm{O}_{2}$ (Airgas, 99.9\%). Pd was grown on $\mathrm{TiO}_{2}$ coated samples by alternating exposures to palladium hexafluoroacetylacetonate $\left(\mathrm{Pd}(\mathrm{hfac})_{2}\right.$, Sigma-Aldrich, 99.9\%) and formalin (HCHO, SigmaAldrich, 37 wt.\% in $\mathrm{H}_{2} \mathrm{O}$ with methanol for stability). The deposition temperatures for metals growth was $250{ }^{\circ} \mathrm{C}$. For Pt-Pd bimetallic nanoparticles growth, the adsorbed Pt precursor was reacted with $\mathrm{O}_{2}$ at $250{ }^{\circ} \mathrm{C}$, and then the adsorbed Pdrpes precursor was reacted with $\mathrm{HCHO}$ at $200{ }^{\circ} \mathrm{C}$. The Pt and Pd metal loadings were determined by X-ray fluorescence spectroscopy (XRF, Oxford ED2000) and inductively coupled plasma (ICP, Varian Vista-MPX). In this work, the bimetallic $\mathrm{Pt}-\mathrm{Pd}$ catalysts prepared using ALD has 1:1 molar ratio on 5-cycle ALD $\mathrm{TiO}_{2}$ coated $\mathrm{Si}(100)$, fused silica, and $\mathrm{SiO}_{2}$ gel.

Scanning Transmission Electron Microscopy (STEM) measurements were made on Pt-Pd bimetallic catalysts on $\mathrm{TiO}_{2}$ coated $\mathrm{SiO}_{2}$ gel. The samples were fully reduced under $50 \mathrm{sccm}$ flow of $3.5 \% \mathrm{H}_{2}$ in $\mathrm{He}$ at $250{ }^{\circ} \mathrm{C}$ for one hour. After sonicating in $10 \mathrm{~mL}$ of isopropanol for $10 \mathrm{~min}$ to obtain a uniformly dispersed slurry, the sample was drop-casted onto a lacey carbon copper TEM grid (SPi Supplies, 400 mesh) and dried carefully by an ultrainfrared lamp. High angle annular dark field (HAADF) images were collected using a JEOL JEM-2100F equipped with a field emission gun (EPIC at Northwestern University).

Propane oxidative dehydrogenation $(\mathrm{ODH})$ was carried out in a micro flow fixed-bed reactor with inside diameter of about $4 \mathrm{~mm}$ under atmospheric pressure. Ten milligrams of the bimetallic catalyst $\mathrm{Pt}-\mathrm{Pd} / \mathrm{TiO}_{2} / \mathrm{SiO}_{2}$ gel was homogeneously diluted in $90 \mathrm{mg}$ silicon carbide with a particle 
size of $44 \mu \mathrm{m}$. For comparison, $\mathrm{Pt} / \mathrm{TiO}_{2} / \mathrm{SiO}_{2}$ gel $(2$ wt $\% \mathrm{Pt})$ and $\mathrm{Pd} / \mathrm{TiO}_{2} / \mathrm{SiO}_{2}$ gel $(1$ wt $\% \mathrm{Pt})$ samples were prepared by ALD with similar particle sizes. The catalysts were calcined under $10 \%$ $\mathrm{O}_{2}$ and $10 \% \mathrm{H}_{2}$ successively at $250{ }^{\circ} \mathrm{C}$ for one hour each. $10 \%$ propane with $2 \mathrm{sccm}$ flow rate and $10 \% \quad \mathrm{O}_{2}$ and $1 \mathrm{sccm}$ flow rate were used as reactants, respectively. Online gas chromatographic analysis was performed on a Hewlett-Packard 5890 GC equipped with a TCD and a FID detector. The conversion of the reaction was defined as the percentage of propane consumed to propane fed. The yield of propylene was obtained as $\mathrm{Y}=\mathrm{X} \times \mathrm{S}$, where $\mathrm{X}$ is the propane conversion and $\mathrm{S}$ is the selectivity to propylene.

X-ray Absorption Spectroscopy (XAS) was performed on Pt-Pd bimetallic catalysts including Extended X-ray absorption fine structure spectroscopy (EXAFS) and X-ray absorption near edge structure spectroscopy (XANES) at the beamline of the Materials Research Collaborative Access Team (MRCAT) at Sector 10-ID of the Advanced Photon Source, Argonne National Laboratory. XAS measurements were made in transmission mode for the $\mathrm{Pd} / \mathrm{TiO}_{2} / \mathrm{SiO}_{2}$ gel powder catalysts. Grazing incidence XAS (GI-XAS) was performed using a partially focused beam $(<50 \mu \mathrm{m})$ for the $\mathrm{Pt}-\mathrm{Pd} / \mathrm{TiO}_{2} /$ fused silica model catalyst with an incident angle $\sim 0.16^{\circ}$, which is below the critical angle of $\mathrm{SiO}_{2}\left(0.20^{\circ}\right)$. A gas-ionization chamber with Soller slits was used to collect the florescence signal. Spectra at both $\mathrm{Pt}_{3}$ edge $(115,627.6 \mathrm{eV})$ and Pd K edge $(24,352.6 \mathrm{eV})$ were acquired for the bimetallic samples. Pt and Pd foils were used to calibrate the monochromator. The samples were fully reduced as it was described above. Then the reactor was purged under $150 \mathrm{sccm}$ flow of ultrahigh purity He for $10 \mathrm{~min}$ at $250{ }^{\circ} \mathrm{C}$. The samples were cooled down to room temperature and measured under $\mathrm{He}$ atmosphere for accurate metal-metal bonds distances and coordination numbers. Standard procedures for EXAFS fitting based on WINXAS 3.1 software were used to fit the data. ${ }^{49}$ The $\mathrm{Pt}-\mathrm{Pt}$ and $\mathrm{Pd}-\mathrm{Pd}$ coordination numbers and bond 
distances were obtained from reference Pd foil for $\mathrm{Pd}-\mathrm{Pd}\left(\mathrm{N}_{\mathrm{Pd}-\mathrm{Pd}}=12\right.$ at $2.75 \AA$ ) and $\mathrm{Pt}$ foil for $\mathrm{Pt}-\mathrm{Pt}\left(\mathrm{N}_{\mathrm{Pt}-\mathrm{Pt}}=12\right.$ at $2.77 \AA$ ̊). $\mathrm{Pt}-\mathrm{Pd}$ and $\mathrm{Pt}-\mathrm{Pd}$ scattering phase shift and amplitudes were constructed by FEFF. A homogeneous Pt-Pd alloy model for FEFF fitting was constructed by substituting Pt with Pd in an fcc bulk structure. A two-shell model fit of the $k^{2}$-weighted EXAFS data was obtained between $k=2.8-12 \AA^{-1}$ and $\mathrm{r}=1.3-3.0 \AA$, respectively. The composition weighted average first shell coordination number $(\mathrm{CN})$ for the 1:1 bimetallic nanoparticles was calculated using: $\mathrm{CN}=\left(\mathrm{CN}_{\mathrm{Pt}-\mathrm{Pt}}+\mathrm{CN}_{\mathrm{Pt}-\mathrm{Pd}}\right) / 2+\left(\mathrm{CN}_{\mathrm{Pd}-\mathrm{Pd}}+\mathrm{CN}_{\mathrm{Pt}-\mathrm{Pd}}\right) / 2$. In-situ $\mathrm{Pt}_{3}$ edge XANES spectra were obtained for $\mathrm{Pt}-\mathrm{Pd} / \mathrm{TiO}_{2} /$ fused silica and $\mathrm{Pt} / \mathrm{TiO}_{2} /$ fused silica samples after introducing $\mathrm{CO}$ gas molecules in the chamber to identify the surface structure of the catalysts.

Ultraviolet resonant photoemission spectroscopy (RPES) was performed at the $3 \mathrm{~m}$ toroidal grating monochromator (TGM) beamline at Center for Advanced Microstructures and Devices (CAMD) at Louisiana State University. The beamline was equipped with a photoemission endstation using a $50 \mathrm{~mm}$ hemispherical electron energy analyzer. $\mathrm{Pd} / \mathrm{TiO}_{2} / \mathrm{SiO}_{2} / \mathrm{Si}(100)$ model catalyst was placed on a Ta sheet for in-situ heating. The sample was first slowly degassed in UHV chamber at $250{ }^{\circ} \mathrm{C}$. After that, the sample was reduced under $3.75 \times 10^{-5}$ Torr ultrahigh purity hydrogen atmosphere at $250{ }^{\circ} \mathrm{C}$ for 30 minutes. The valence band spectra were acquired after cooling down the sample to room temperature in UHV. The incident photon energy was tuned in the range from 35 to $96 \mathrm{eV}$.

\section{RESULTS AND DISSUSSION}

Model catalysts used in this work were prepared on fused silica and $\operatorname{Si}(100)$, respectively. The use of the amorphous fused silica is critical to the success of GI-XAS measurements. In the 
contrary, the crystalline wafer such as $\mathrm{Si}(100)$ would generate diffraction patterns in the EXAFS spectra, leading to poor data quality and complicating the data analysis. ${ }^{50}$ The samples for RPES measurements were prepared on boron and phosphorus doped $\operatorname{Si}(100)$ wafers with resistivity about $70 \mathrm{ohm}-\mathrm{cm}$ as the accuracy of RPES experiments benefits from using conductive substrates. Nonetheless, the surface of fused silica and $\mathrm{Si}(100)$ was covered with $\mathrm{ALD} \mathrm{TiO}_{2}$ thin film to create similar chemical environment for chemical reactions.

The formation of Pt-Pd bimetallic nanoparticles were confirmed by STEM HAADF image of $\mathrm{Pt}-\mathrm{Pd} / \mathrm{TiO}_{2} / \mathrm{SiO}_{2}$ gel after $\mathrm{H}_{2}$ reduction on TEM grid as shown in Fig. 1. HAADF image shows brighter contrast for higher Z-number elements which is proportional to $\mathrm{Z}^{2}$. Therefore, it was identified that the bright contrast Pt-Pd nanoparticles were formed and distributed uniformly on $\mathrm{TiO}_{2} / \mathrm{SiO}_{2}$ gel matrix with dark contrast because the nucleation properties of $\mathrm{Pt}$ and $\mathrm{Pd}$ are greatly improved on $\mathrm{TiO}_{2}$. The average diameter of the Pt-Pd nanoparticles is $\sim 1.2 \mathrm{~nm}$.

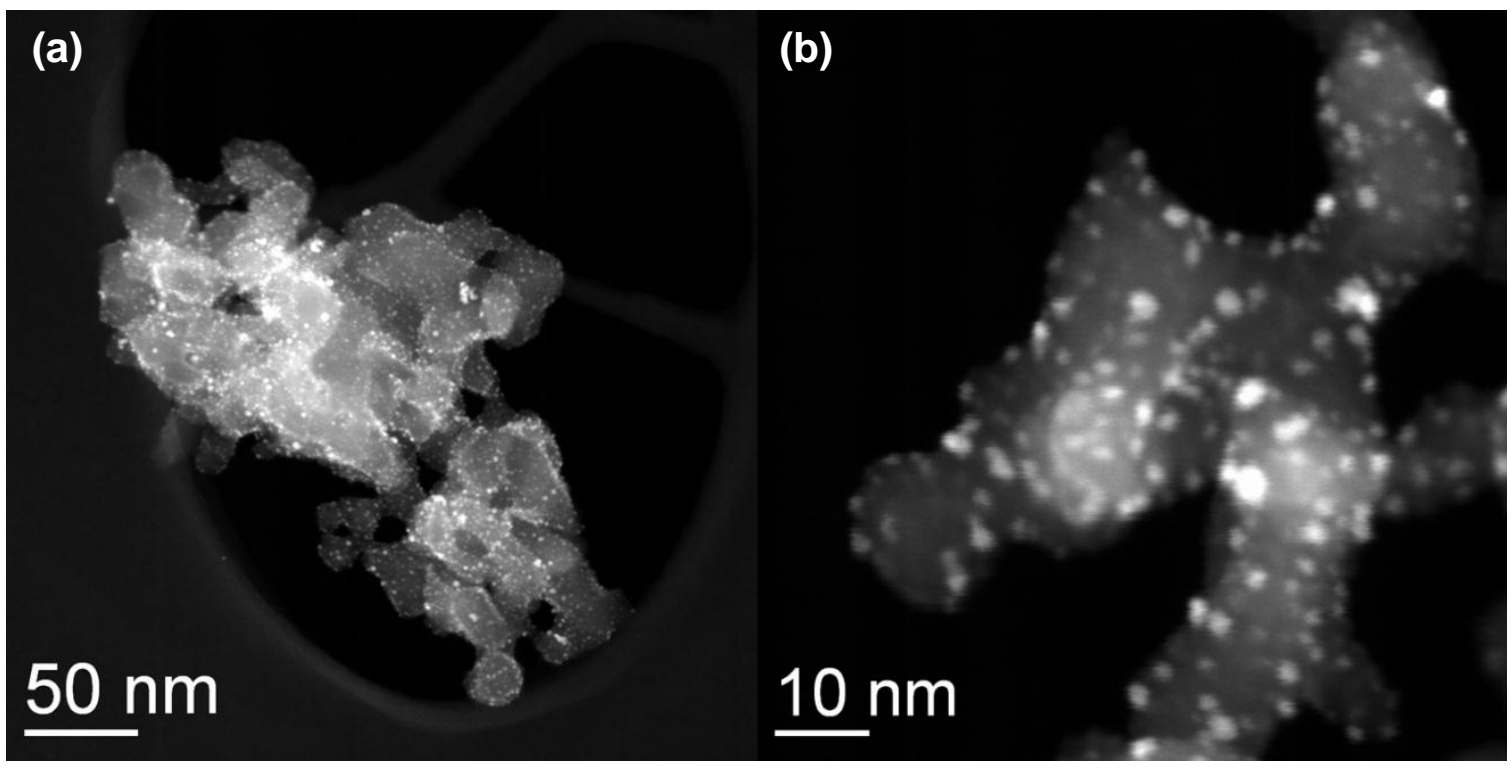

Figure 1. HAADF STEM images of the reduced $\mathrm{Pt}-\mathrm{Pd} / \mathrm{TiO}_{2} / \mathrm{SiO}_{2}$ gel catalyst. 
The catalytic performances of Pt-Pd bimetallic nanoparticles were directly compared with monometallic $\mathrm{Pt} / \mathrm{TiO}_{2} / \mathrm{SiO}_{2}$ gel and $\mathrm{Pd} / \mathrm{TiO}_{2} / \mathrm{SiO}_{2}$ gel for identifying the synergetic effect of bimetallic catalysts by evaluating the oxidative dehydrogenation of propane to propylene at the temperature range from $300{ }^{\circ} \mathrm{C}$ to $500{ }^{\circ} \mathrm{C}$. While $\mathrm{TiO}_{2} / \mathrm{SiO}_{2}$ is not active for propane $\mathrm{ODH}$, the loading of $\mathrm{TiO}_{2}$ could affect the catalyst performance, ${ }^{51}$ therefore the loading of $\mathrm{TiO}_{2}$ was kept as a constant at $\sim 8 \mathrm{wt} \%$ by applying five ALD cycles of $\mathrm{TiO}_{2}$ on $\mathrm{SiO}_{2}$. As shown in Fig. 2 (a), the conversion to propylene in Pt-Pd bimetallic catalyst is significantly improved compared to Pt and Pd monometallic catalysts throughout the entire temperature range. In particular, the conversion to propylene in Pt-Pd bimetallic catalyst is about $40 \%$ above $450{ }^{\circ} \mathrm{C}$ while that of $\mathrm{Pt}$ and $\mathrm{Pd}$ monometallic catalysts stay below $20 \%$. Moreover, the propylene yield is significantly higher in Pt-Pd bimetallic catalyst especially above $400{ }^{\circ} \mathrm{C}$ as shown in Fig. 2(b). The yield of propylene for Pt-Pd bimetallic catalyst is peaked at $400{ }^{\circ} \mathrm{C}$ with about $4.0 \%$ of value while that of $\mathrm{Pt}$ and Pd monometallic catalysts are about $0.5 \%$ and $2.2 \%$, respectively. Therefore, it is clear that the formation of bimetallic Pt-Pd nanoparticles on $\mathrm{TiO}_{2}$ support gives a great enhancement on the catalytic activities compared to $\mathrm{Pt}$ and/or $\mathrm{Pd}$ monometallic catalysts on $\mathrm{TiO}_{2}$. Hence, the fundamental understanding on the structural and electronic properties of Pt-Pd bimetallic catalysts using surface analysis techniques including GI-XAS and RPES is necessary. 


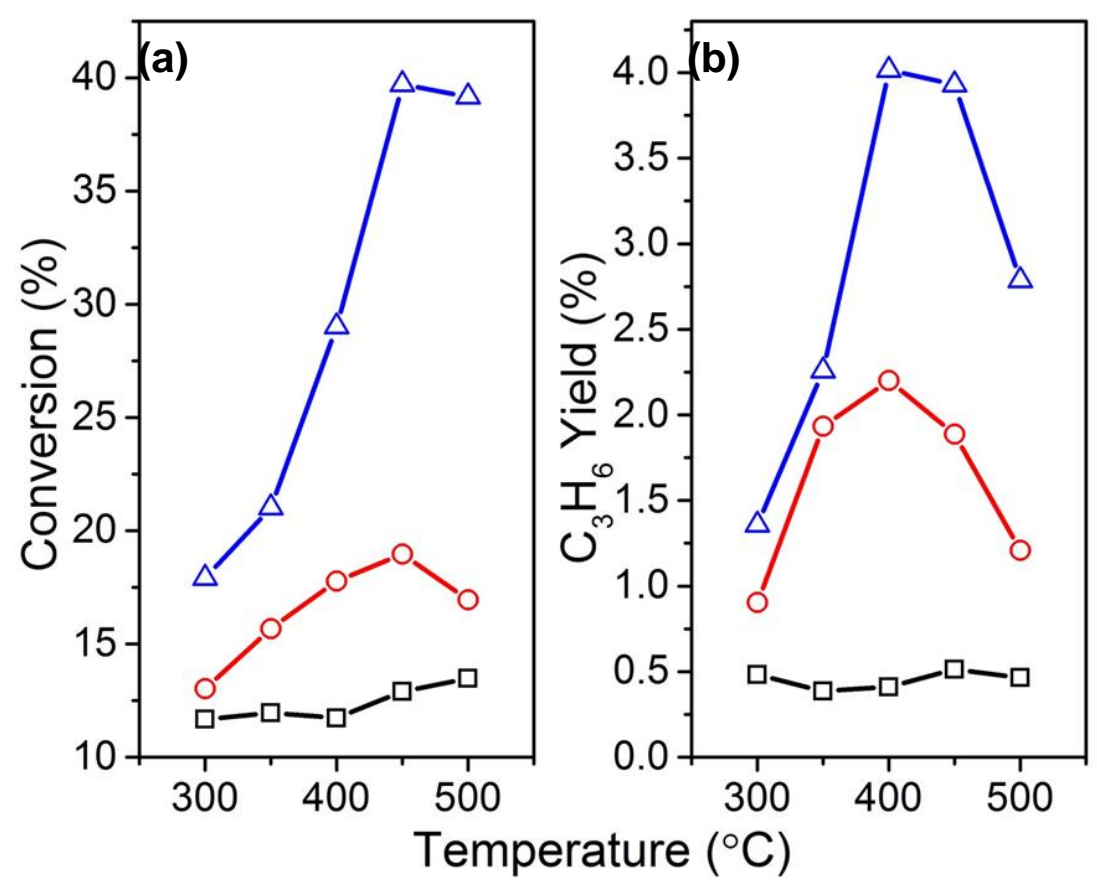

Figure 2. Performance of catalysts in propane ODH. (a) Conversion of propane, and (b) yield of propylene of $\mathrm{Pt}-\mathrm{Pd} / \mathrm{TiO}_{2} / \mathrm{SiO}_{2}$ catalyst (Blue), $\mathrm{Pd} / \mathrm{TiO}_{2} / \mathrm{SiO}_{2}$ (Red), and $\mathrm{Pt} / \mathrm{TiO}_{2} / \mathrm{SiO}_{2}$ (Black) catalysts, respectively.

To identify the bonding nature of Pt-Pd bimetallic nanoparticles on $\mathrm{TiO}_{2} /$ fused silica, synchrotron GI-XAS measurements were carried out for Pt $\mathrm{L}_{3}$ edge and Pd K edge. GI-XAS was used to enhance the signal from the very thin surface layer. Because of its high reactivity, Pt-Pd nanoparticles were oxidized upon air exposure. Therefore, it is necessary to reduce the changes caused by air exposure prior to GI-XAS measurements by hydrogen annealing as described in the experimental section. Even with the surface enhancement from GI-XAS the amount of Pd was not enough to obtain smooth EXAFS oscillation with sufficient signal to noise ratio in high 
$\mathrm{k}$ region. To avoid the confusion due to high noise, Pd K edge XAFS data were not be fitted. XANES Pt $\mathrm{L}_{3}$ and $\mathrm{Pd} \mathrm{K}$ edges for Pt-Pd bimetallic catalysts on $\mathrm{TiO}_{2} /$ fused silica (Blue) are shown in Fig. 3 (a) and (b). XANES spectra for Pt and Pd monometallic catalysts $\mathrm{TiO}_{2} /$ fused silica (Red) are shown for the comparison. Interestingly, the intensity of $\mathrm{Pt} \mathrm{L}_{3}$ edge whiteline (WL) is significantly higher after forming Pt-Pd bimetallic nanoparticles compared to $\mathrm{Pt}$ monometallic nanoparticles. Previous reports for XANES study on Pt-Pd bimetallic nanoparticles have observed the same behavior. ${ }^{52-54}$ Since the $\mathrm{Pt} \mathrm{L}_{3}$ edge involves a transition from occupied $2 p_{3 / 2}$ to partially unoccupied $5 d_{3 / 2}$ and $5 d_{5 / 2}$ states, the hole density of $5 d$ states are proportional to the intensity of the WL. Therefore, Pt-Pd alloying produces an electron transition from $\mathrm{Pt}$ to $\mathrm{Pd} 4 d$ states which results in $\mathrm{Pt} \mathrm{L}_{3}$ edge WL intensity increase. Even though bulk $\mathrm{Pd}$ has fully occupied $4 d$ orbital configuration, nano-sized Pd loses $4 d$ electrons due to the coordination reduction and the $s-d$ orbital hybridization. ${ }^{55}$ Hence, the charge transfer from Pt $5 d$ to Pd $4 d$ orbital can happen when it becomes a nano-sized catalyst as shown in Fig. 1. On the other hand, Pd K edge WL shows similar height of intensity for both Pt-Pd bimetallic and Pd monometallic catalysts because the cross-section of the $1 s$ to $4 d$ transition in Pd K edge is limited by the selection rule. ${ }^{53}$ EXAFS data for Pt and Pd in Fig. 3 (c) and (d), respectively show significant changes after forming bimetallic Pt-Pd nanoparticles compared to $\mathrm{Pt}$ and $\mathrm{Pd}$ monometallic nanoparticles in the magnitude and imaginary parts of the EXAFS signals, which indicates a second nearest-neighbor scatterer upon alloying. ${ }^{56,57}$ The detailed EXAFS fitting results for the Pt-Pd bimetallic nanoparticles are listed in Table I. As it was described above, the total coordination numbers for Pt-Pd bimetallic and Pt monometallic nanoparticles are 10.2 and 5.3, respectively which are smaller than 12 of the bulk sample (Pt foil). It has a good agreement with the fact that the coordination reduction occurs with the formation of nano-sized catalysts. In 
addition, Pt monometallic sample has a shorter Pt-Pt bond distance and a smaller coordination number compared to that of $\mathrm{Pt}-\mathrm{Pd}$ monometallic sample because the smaller size of $\mathrm{Pt}$ nanoparticles affect the bond length as well as the coordination number. ${ }^{58}$
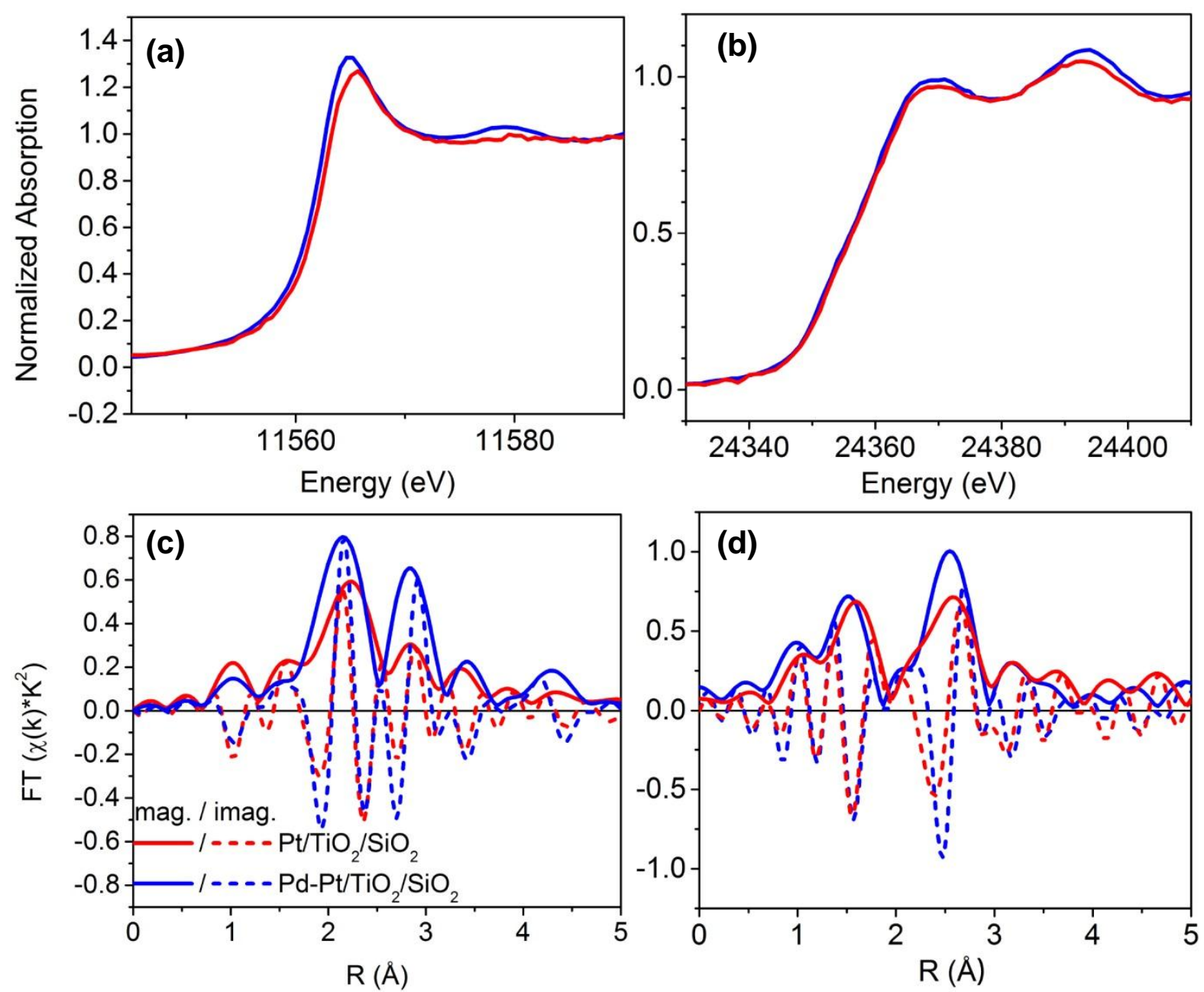

Figure 3. XANES (a) $\mathrm{Pt} \mathrm{L}_{3}$ edge for $\mathrm{Pt} / \mathrm{TiO}_{2} /$ fused silica (Red) and $\mathrm{Pt}-\mathrm{Pd} / \mathrm{TiO}_{2} /$ fused silica samples (Blue) and (b) $\mathrm{Pd} \mathrm{K}$ edge for $\mathrm{Pd} / \mathrm{TiO}_{2} /$ fused silica (Red) and $\mathrm{Pt}-\mathrm{Pd} / \mathrm{TiO}_{2} /$ fused silica samples (Blue). Fourier transformed $k^{2}$-weighted EXAFS data of (c) $\mathrm{Pt} \mathrm{L}_{3}$ edge for $\mathrm{Pt} / \mathrm{TiO}_{2} /$ fused silica (Red) and Pt-Pd/TiO $/$ fused silica samples, $k=3.1-9.5 \AA^{-1}$, and (d) $\mathrm{Pd} \mathrm{K}$ edge for $\mathrm{Pd} / \mathrm{TiO}_{2} /$ fused silica (Red) and Pt-Pd/TiO $/$ fused silica samples (Blue), $k=2.8-9.8 \AA^{-1}$. 
Table I. EXAFS Data Fitting Results of Pt-Pd Bimetallic and Pt Monometallic Samples and Pt foil.

\begin{tabular}{cccccc}
\hline Samples & Scatter & $\mathrm{CN}^{\mathrm{a}}$ & $\mathrm{D}(\AA)^{\mathrm{b}}$ & $\sigma^{2}\left(\times 10^{3}\right)$ & $\mathrm{E}_{0}(\mathrm{eV})$ \\
\hline $\mathrm{Pt}$ foil & $\mathrm{Pt}-\mathrm{Pt}$ & 12 & 2.76 & 4 & 7.8 \\
$\mathrm{Pt} / \mathrm{TiO}_{2} /$ fused silica & $\mathrm{Pt}-\mathrm{Pt}$ & 5.3 & 2.67 & 6 & 1.8 \\
& $\mathrm{Pt}-\mathrm{Pt}$ & 7.2 & 2.73 & 6 & 3.9 \\
$\mathrm{Pt}-\mathrm{Pd} / \mathrm{TiO}_{2} /$ fused silica & $\mathrm{Pt}-\mathrm{Pd}$ & 3.0 & 2.73 & 5 & 7.5 \\
\hline \hline
\end{tabular}

\footnotetext{
${ }^{\mathrm{a}} \mathrm{CN}$-coordination number

${ }^{\mathrm{b}} \mathrm{D}$ - bond distance
}

To verify the catalytic reaction on bimetallic nanoparticles after gas adsorption, in-situ $\mathrm{Pt}_{3}$ edge XANES spectra were obtained after introducing CO gas molecules on the samples at room temperature as shown in Fig. 4 (a). The spectra were taken in the CO flow. In the monometallic $\mathrm{Pt} / \mathrm{TiO}_{2} /$ fused silica sample, $\mathrm{Pt} \mathrm{L}_{3}$ edge $\mathrm{WL}$ intensity increases which indicates that the electronic charge transfer occurs between $\mathrm{Pt}$ and $\mathrm{CO}$. This is contrary to the $\mathrm{Pt} \mathrm{L}_{3}$ edge WL of Pt$\mathrm{Pd} / \mathrm{TiO}_{2} /$ fused silica which does not show any changes in WL intensity indicating that $\mathrm{Pt}$ is not involved in catalytic activity. This strongly indicates that the Pt-Pd has a Pd shell/Pt core structure as it is depicted in Fig. 4 (b) and it is consistent with the reported DFT calculations. ${ }^{45}$ 
Hence, it is crucial to observe the electronic states of Pd atoms in bimetallic structure using RPES.

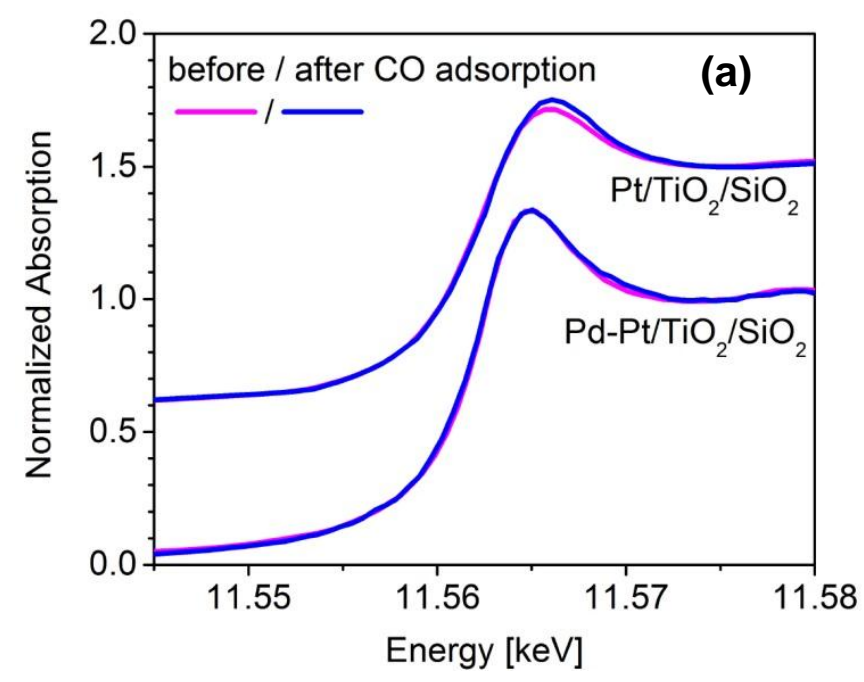

(b)
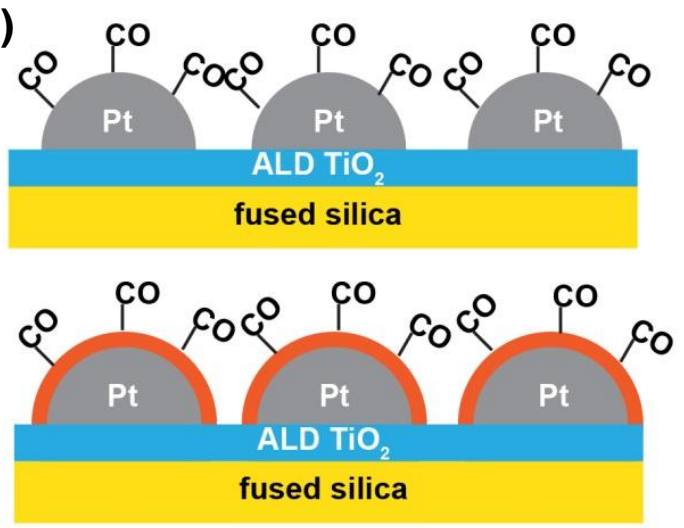

Figure 4. (a) XANES $\mathrm{Pt} \mathrm{L}_{3}$ edge for $\mathrm{Pt} / \mathrm{TiO}_{2} /$ fused silica and $\mathrm{Pt}-\mathrm{Pd} / \mathrm{TiO}_{2} /$ fused silica samples before/after $\mathrm{CO}$ adsorption. (b) A schematic of $\mathrm{Pt}$ and $\mathrm{Pt}-\mathrm{Pd} / \mathrm{TiO}_{2} /$ fused silica model catalyst. $\mathrm{Pd}$ shell covers Pt nanoparticles so that the reaction with CO only occurs with Pd surface.

Fig. 5 shows the RPES valence spectra for Pt-Pd bimetallic nanoparticles on $\mathrm{TiO}_{2} / \mathrm{Si}(100)$ substrate. The incident photon energy varies from $35 \mathrm{eV}$ to $96 \mathrm{eV}$ to assess the resonance characteristics of $\mathrm{Pd}$ atoms. It is well known that the photoionization cross-sections for $4 d$ valence states are influenced by many-body effects which gives a strong resonance at the incident energy of $70 \mathrm{eV}$ for Pd atoms. ${ }^{59}$ In Fig. 5, Pd resonance occurs in the incident energy range from $58 \mathrm{eV}$ to $95 \mathrm{eV}$ so that the intensity is significantly increases in the binding energy range from 0 to $4 \mathrm{eV}$ as previously reported for $\mathrm{Pd} / \mathrm{TiO}_{2} / \mathrm{Si}(100)$ model catalysts. ${ }^{46}$ In addition 
the degree of resonant enhancement is slightly higher in $\mathrm{Pt}-\mathrm{Pd} / \mathrm{TiO}_{2} / \mathrm{Si}(100)$ bimetallic catalysts than that of $\mathrm{Pd} / \mathrm{TiO}_{2} / \mathrm{Si}(100)$ even though there are fewer Pd atoms in the system. We note that the resonant intensity decreases above an energy of $85 \mathrm{eV}$ in contrast to $70 \mathrm{eV}$ observed in $\mathrm{Pd} / \mathrm{TiO}_{2} / \mathrm{Si}(100)$ system. Observing a continued resonance enhancement above $70 \mathrm{eV}$ also supports strongly the $d$-orbital hybridization involving charge transfer from $\mathrm{Pt} 5 d$ to $\mathrm{Pd} 4 d$, significantly affecting the electronic states of Pt-Pd bimetallic catalysts. The maximum density of states can be obtained when the photon direct transition occurs to the strongly broadened electron states. ${ }^{59}$ Therefore, the enhanced $\mathrm{Pd} 4 d$ resonance indicates the broadening of the electronic states after the bimetallic Pt-Pd nanoparticles form, with $d$-orbital hybridization. As the catalytic reaction activity occurs on the Pd shell in the bimetallic Pt-Pd catalysts, it is plausible that the bimetallic Pt-Pd catalysts has a synergetic improvement of catalytic behavior compared to Pt and Pd monometallic catalysts due to this $d$ orbital hybridization. 


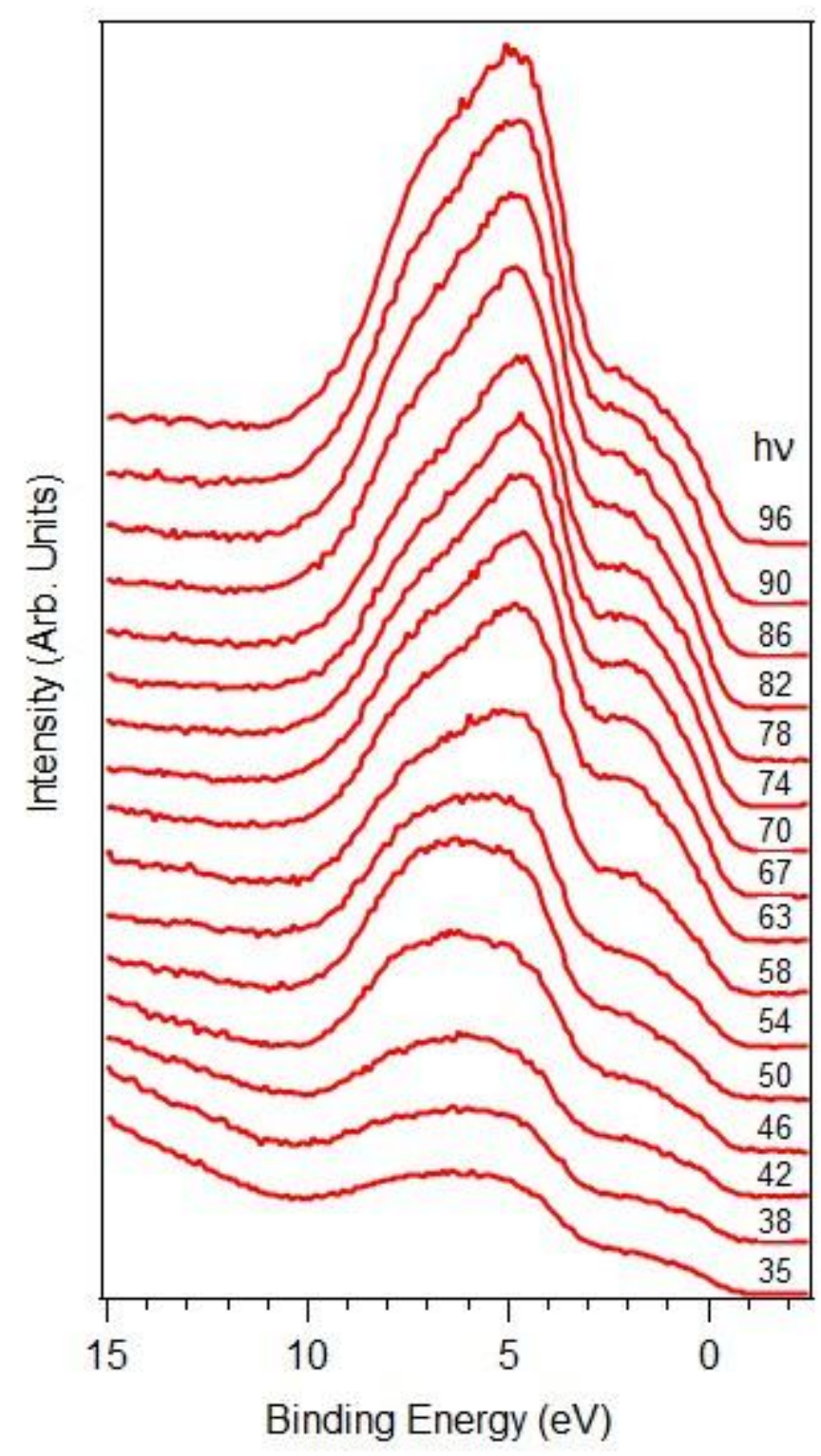

Figure 5. RPES valence spectra for $\mathrm{Pt}-\mathrm{Pd} / \mathrm{TiO}_{2} / \mathrm{Si}(100)$ sample with the incident photon energy range from 35 to $96 \mathrm{eV}$. Intensity increase in the binding energy range from 0 to $4 \mathrm{eV}$ is observed due to $\mathrm{Pd}$ resonance at the incident energy of $70 \mathrm{eV}$. Compared to spectra from $\mathrm{Pd} / \mathrm{TiO}_{2} / \mathrm{Si}(100)$ in the previous report, the resonance has been intensified due to $d$-orbital charge transfer from $\mathrm{Pt}$ to $\mathrm{Pd}$. 


\section{CONCLUSION}

In summary, the Pt-Pd bimetallic model catalyst and powder catalyst supported by $\mathrm{TiO}_{2}$ were prepared for characterizing catalyst performance and evaluating their electronic properties by performing surface analysis. The $\mathrm{Pt}-\mathrm{Pd} / \mathrm{TiO}_{2} /$ fused silica and $\mathrm{Pt}-\mathrm{Pd} / \mathrm{TiO}_{2} / \mathrm{Si}(100)$ were characterized using GI-XAS and RPES, respectively. The performance of Pt-Pd/TiO $/ 2 / \mathrm{SiO}_{2}$ gel powder catalysts were examined in the propane ODH. After forming bimetallic Pt-Pd nanoparticles, the catalytic performance is significantly improved compared to $\mathrm{Pt}$ and $\mathrm{Pd}$ monometallic catalysts. GI-XAS study shows that the d electron transfer from $\mathrm{Pt} 5 d$ to $\mathrm{Pd} 4 d$ upon alloying. In addition, the structure of Pt-Pd nanoparticles was revealed as Pd shell/Pt core structure from the in-situ GI-XAS study with CO adsorption. RPES spectra of Pt-Pd bimetallic model catalyst shows a measurable enhancement on $\mathrm{Pd} 4 d$ resonance because of the orbital hybridization and electronic states broadening of $\mathrm{Pt}$ and $\mathrm{Pd}$ which may lead to a significant improvement on the catalytic performance of bimetallic Pt-Pd catalysts.

\section{ACKNOWLEDGEMENTS}

This work is supported by the ACS Petroleum Research Fund (PRF\# 56197-DNI5). Use of the Advanced Photon Source was supported by the U. S. Department of Energy, Office of Science, Office of Basic Energy Sciences, under Contract No. DE-AC02-06CH11357. MRCAT operations are supported by the Department of Energy and the MRCAT member institutions. Use of the Center for Nanoscale Materials was supported by the U. S. Department of Energy, Office of 
Science, Office of Basic Energy Sciences, under Contract No. DE-AC02-06CH11357.

\section{REFERENCES}

1. Y.-G. Guo, J.-S. Hu and L.-J. Wan, Adv. Mater. 20 (15), 2878-2887 (2008).

2. S. Damyanova and J. M. C. Bueno, Appl. Catal., A 253 (1), 135-150 (2003).

3. J. Lu, K.-B. Low, Y. Lei, J. A. Libera, A. Nicholls, P. C. Stair and J. W. Elam, Nat. Commun. 5, 3264 (2014).

4. W. Yu, M. D. Porosoff and J. G. Chen, Chem. Rev. 112, 5780-5817 (2012).

5. E. C. Wegener, Z. Wu, H.-T. Tseng, J. R. Gallagher, Y. Ren, R. E. Diaz, F. H. Ribeiro and J. T. Miller, Catal. Today 299, 146-153 (2018).

6. X. F. Wang, H. Y. Zhao, T. P. Wu, Y. Z. Liu and X. H. Liang, Catal. Lett. 146 (12), 2606-2613 (2016).

7. J. Wu, Z. Peng and A. T. Bell, J. Catal. 311, 161-168 (2014).

8. P. J. Dietrich, M. C. Akatay, F. G. Sollberger, E. A. Stach, J. T. Miller, W. N. Delgass and F. H. Ribeiro, ACS Catal. 4, 480-491 (2014).

9. E. P. Maris, W. C. Ketchie, M. Murayama and R. J. Davis, J. Catal. 251, 281-294 (2007).

10. C. Hammond, R. L. Jenkins, N. Dimitratos, J. A. Lopez-Sanchez, M. H. ab Rahim, M. M. Forde, A. Thetford, D. M. Murphy, H. Hagen, E. E. Stangland, J. M. Moulijn, S. H. Taylor, D. J. Willock and G. J. Hutchings, Chemistry-a European Journal 18 (49), 15735-15745 (2012).

11. J. R. Kitchin, J. K. Nørskov, M. A. Barteau and J. G. Chen, Phys. Rev. Lett. 93 (15), 156801 (2004).

12. J. Lu, J. W. Elam and P. C. Stair, Acc. Chem. Res. 46 (8), 1806-1815 (2013).

13. S. T. Christensen, H. Feng, J. L. Libera, N. Guo, J. T. Miller, P. C. Stair and J. W. Elam, Nano Lett. 10 (8), 3047-3051 (2010).

14. M. Chen, D. Kumar, C.-W. Yi and D. W. Goodman, Science 310 (5746), 291 (2005).

15. C. A. Rodriguez-Proenza, J. P. Palomares-Baez, M. A. Chavez-Rojo, A. F. Garcia-Ruiz, C. L. Azanza-Ricardo, A. Santovena-Uribe, G. Luna-Barcenas, J. L. Rodriguez-Lopez and R. Esparza, Materials 11 (10), 1882 (2018).

16. R. Mendoza-Pérez and G. Guisbiers, Nanotechnology 30, 305702 (2019).

17. R. M. Navarro, B. Pawelec, J. M. Trejo, R. Mariscal and J. L. G. Fierro, J. Catal. 189 (1), 184-194 (2000).

18. A. Gutiérrez, J. M. Arandes, P. Castaño, M. Olazar, A. Barona and J. Bilbao, Fuel Process. Technol. 95, 8-15 (2012).

19. M. Skoglundh, L. O. Löwendahl and J. E. Otterated, Appl. Catal. 77 (1), 9-20 (1991).

20. H. Kobayashi, M. Yamauchi, H. Kitagawa, Y. Kubota, K. Kato and M. Takata, J. Am. Chem. Soc. 
132 (16), 5576-5577 (2010).

21. Z. Peng and H. Yang, J. Am. Chem. Soc. 131 (22), $7542-7543$ (2009).

22. D. G. Castner, B. A. Sexton and G. A. Somorjai, Surf. Sci. 71 (3), 519-540 (1978).

23. R. Imbihl and G. Ertl, Chem. Rev. 95 (3), 697-733 (1995).

24. C. T. Campbell, Surf. Sci. Rep. 27 (1), 1-111 (1997).

25. C. R. Henry, Surf. Sci. Rep. 31 (7), 231-325 (1998).

26. M. Baumer and H. J. Freund, Prog. Surf. Sci. 61 (7-8), 127-198 (1999).

27. D. W. Goodman, Chem. Rev. 95 (3), 523-536 (1995).

28. U. Diebold, Surf. Sci. Rep. 48, 53-229 (2003).

29. B. J. O'Neill, D. H. K. Jackson, J. Lee, C. Canlas, P. C. Stair, C. L. Marshall, J. W. Elam, T. F. Kuech, J. A. Dumesic and G. W. Huber, ACS Catal. 5 (3), 1804-1825 (2015).

30. T. D. Gould, A. M. Lubers, A. R. Corpuz, A. W. Weimer, J. L. Falconer and J. W. Medlin, ACS Catal. 5 (2), 1344-1352 (2015).

31. A. C. Kozen, C.-F. Lin, A. J. Pearse, M. A. Schroeder, X. Han, L. Hu, S.-B. Lee, G. W. Rubloff and M. Noked, ACS Nano 9 (6), 5884-5892 (2015).

32. S. M. George, Chem. Rev. 110 (1), 111-131 (2010).

33. B. S. Lim, A. Rahtu and R. G. Gordon, Nature Mater. 2 (11), 749-754 (2003).

34. Z. Lu, B. Liu, B. Zhang, Z. Gan, S. Tang, L. Ma, T. Wu, G. J. Nelson, Y. Qin, C. H. Turner and Y. Lei, J. Catal. 377, 419-728 (2019).

35. T. D. Gould, A. M. Lubers, A. R. Corpuz, A. W. Weimer, J. L. Falconer and J. W. Medlin, ACS Catal. 5, 1344-1352 (2015).

36. X. R. Jiang, H. Huang, F. B. Prinz and S. F. Bent, Chem. Mater. 20 (12), 3897-3905 (2008).

37. B. Zhang and Y. Qin, ACS Catal. 8 (11), 10064-10081 (2018).

38. Y. Lei, S. Lee, K.-B. Low, C. L. Marshall and J. W. Elam, ACS Catal. 6 (6), 3457-3460 (2016).

39. F. Zaera, J. Phys. Chem. Lett. 3 (10), 1301-1309 (2012).

40. Y. Lei, B. Liu, J. L. Lu, X. Lin, L. Gao, N. Guisinger, J. P. Greeley and J. W. Elam, Phys. Chem. Chem. Phys. 17, 6470-6477 (2015).

41. Y. Lei, F. Mehmood, S. Lee, J. Greeley, B. Lee, S. Seifert, R. E. Winans, J. W. Elam, R. J. Meyer, P. C. Redfern, D. Teschner, R. Schlogl, M. J. Pellin, L. A. Curtiss and S. Vajda, Science 328 (5975), 224-228 (2010).

42. J. Lu, B. Fu, M. C. Kung, G. Xiao, J. W. Elam, H. H. Kung and P. C. Stair, Science 335 (6073), 1205 (2012).

43. A. Santasalo-Aarnio, E. Sairanen, R. M. Arán-Ais, M. C. Figueiredo, J. Hua, J. M. Feliu, J. Lehtonen, R. Karinen and T. Kallio, J. Catal. 309, 38-48 (2014).

44. M. J. Weber, A. J. M. Mackus, M. A. Verheijen, C. van der Marel and W. M. M. Kessels, Chem. Mater. 24 (15), 2973-2977 (2012). 
45. Y. Lei, B. Liu, J. Lu, R. J. Lobo-Lapidus, T. Wu, H. Feng, X. Xia, A. U. Mane, J. A. Libera, J. P. Greeley, J. T. Miller and J. W. Elam, Chem. Mater. 24 (18), 3525-3533 (2012).

46. Z. Lu, O. Kizilkaya, A. J. Kropf, M. Piernavieja-Hermida, J. T. Miller, R. L. Kurtz, J. W. Elam and Y. Lei, Catal. Sci. Technol. 6 (18), 6845-6852 (2016).

47. H.-B.-R. Lee and S. F. Bent, Chem. Mater. 24 (2), 279-286 (2012).

48. J. Lu and P. C. Stair, Langmuir 26 (21), 16486-16495 (2010).

49. D. Friebel, D. J. Miller, C. P. O'Grady, T. Anniyev, J. Bargar, U. Bergmann, H. Ogasawara, K. T. Wikfeldt, L. G. M. Pettersson and A. Nilsson, Phys. Chem. Chem. Phys. 13 (1), 262-266 (2011).

50. Z. Lu, O. Kizikaya, A. J. Kropf, M. Piernavieja-Hermida, J. T. Miller, R. Kurtz, J. W. Elam and Y. Lei, Catal. Sci. Tech. 6, 6845-6852 (2016).

51. S. Chakraborty, S. C. Nayak and D. Goutam, Catal. Today 254 (1), 62-71 (2015).

52. Y. Yu, B. Fonfé, A. Jentys, G. L. Haller, J. A. R. van Veen, O. Y. Gutiérrez and J. A. Lercher, J. Catal. 292, 1-12 (2012).

53. S. J. Cho and S. K. Kang, Catal. Today 93-95, 561-566 (2004).

54. J. Li, C.-H. Liu, M. N. Banis, D. Vaccarello, Z.-F. Ding, S.-D. Wang and T.-K. Sham, J. Phys. Chem. C 121 (44), 24861-24870 (2017).

55. J. Li, T.-K. Sham, Y. Ye, J. Zhu and J. Guo, J. Phys. Chem. C 119 (4), 2222-2230 (2015).

56. F. Bernardi, A. Traverse, L. Olivi, M. C. M. Alves and J. Morais, J. Phys. Chem. C 115 (25), 12243-12249 (2011).

57. K. K. Bando, T. Kawai, K. Asakura, T. Matsui, L. Le Bihan, H. Yasuda, Y. Yoshimura and S. T. Oyama, Catal. Today 111 (3), 199-204 (2006).

58. Y. Lei, J. Jelic, L. C. Nitsche, R. Meyer and J. Miller, Top. Catal. 54 (5), 334-348 (2011).

59. P. O. Nilsson, C. G. Larsson and W. Eberhardt, Phys. Rev. B 24 (4), 1739-1743 (1981). 